\title{
DATA HOARDING AND INFORMATION CLUTTER: THE IMPACT ON COST, LIFE SPAN OF DATA, EFFECTIVNESS, SHARING, PRODUCTIVITY AND KNOWLEDGE MANAGEMENT CULTURE
}

\author{
Cynthia J. Gormley, Robert Morris University, cjgst16@mail.rmu.edu \\ Samantha J. Gormley, Robert Morris University, sjgst19@mail.rmu.edu
}

\begin{abstract}
Data clutter is all around us. This may apply to the computer you are reading this on or your employer's data warehouse or collection center. What makes us data hoarders? For some, this may be as basic as not knowing what information is needed, the fear of removing collected data because at one time it served a purpose, or having relevant data but not knowing what to do with it. Similar to the land of the lost file cabinets, data sits in a file waiting to be discarded, taking up virtual space. For others, the answer is more complex. Cost, effectiveness, life span of data, who shares the data or information, productivity and knowledge management culture, may all play a part in the answer. The purpose of this study is to explore the reasons why people hoard data and the impact the hoarding plays in relation to business culture. Findings show the areas of business most affected by data hording are cost, lifespan of data, effectiveness, sharing, productivity, and knowledge management.
\end{abstract}

Keywords: Data/Information Hoarding, Information Management, Data Clutter

\section{INTRODUCTION}

Data gives information substance. But how much data do we need to collect to determine the information we need? In collecting the data, are too many questions being asked and data being accumulated not finding a used? How long is it being retained and is it being shared? Is data hoarding necessary given today's technology and the internet's data collection? In searching for these answers, this paper explores hoarding as a problem that individuals and organizations face daily. This paper will discuss data and information hoarding in perspective to cost, life span of data, effectiveness, sharing information, productivity and the culture of knowledge management.

Hoarding, as described by the Mayo Clinic is, "excessive collection of items, along with the inability to discard them. Hoarding often creates such cramped living conditions that homes may be filled to capacity, with only narrow pathways winding through stacks of clutter" [12]. Data, for the purpose of this paper, could be any information, research or collection. It may be words or numbers. "Information today has several specific meanings. It is understood to mean knowledge one gains through study, research, and instruction" [16]. Information is produced by data. When data produces information, knowledge may be obtained from the examination of the conclusions of facts. "Where knowledge and information overlap is that they both mean a body of facts and something that is known" [16]. By collecting the information (data) and having the inability to discard or recycle the information, or not to know that this must be done, data hoarding becomes a reality.

Data clutter is all around us. This may well apply to the computer you may be reading this on or your employer's data warehouse or collection center. What makes us data hoarders? The answer, for some, may be as basic as not knowing what may be need or the fear of removing data that was collected for a purpose and now don't know what to do with it. Similar to the land of the lost file cabinets, data sits in a file waiting to be discarded, taking up virtual space. For others, the answer is more complex. Cost, effectiveness, life span of data, who shares the data or information, productivity and knowledge management culture, may all play a part in the answer. 


\section{Issues in Information Systems}

Volume 13, Issue 2, pp. 90-95, 2012

\section{Cost}

Cost is a problem for data hoarders. Space costs become more expensive based on electricity used. "So heavy are the current energy demands of our expanding data usage that the U.S Environmental Protection Agency had pegged servers and data centers as responsible for nearly two percent of total national electrical consumption" [15]. This need is growing based on trends. Environmentally, hoarding costs not only the user, but society as well based on the measurable carbon footprint. Also included in cost is the storage of the data. More memory, larger data warehousing systems, more places to store the data.

Another form of cost is time, especially considering deadlines, for example:

“... Your team, maybe 20 people, your division, 2,000 people, your subsidiary, 20,000 people and so on. And then consider, the number of people whom you cc'ed on your last note, It was 15, wasn't it? Or was it, as a recent e-mail I saw, more like 300 After all, e-mail is a great way to keep people informed - or is it? It wasn't even the cc'ing of the 300. Only 10 people really needed to get that note, but the other 290 each lost may be five minutes $f$ their day, That was, until a colleague hit the reply to all. Let's stop and recap for a moment. By including 290 people unnecessarily in the email, the sender was responsible for the loss of a minimum of 24 hours of colleague's time [16].

Other cost factors with hoarding could include lost files, data that is not information, and the high cost of storage space that may not be needed if files are maintain accurately. File retention of unneeded data may cause some not only high cost for storage but again may entice users to be hoarders willingly or unwillingly. Determining the life span of the data will help determine what should stay and what should go.

\section{Life span of data}

Data in the twenty first century has a shorter life span. Before 1959, a piece of knowledge was profitable for 21.8 years; since 1990, it is only profitable for 3.2 years. "This shows that knowledge is no longer so valuable a stock" [7]. Data today is often kept for historical reasons. If the data is only profitable for 3.2 years, how should the historic information be salvaged? And once the reports are completed, does all of the data need to be salvaged? "Today's information has such a painfully short shelf life, what could be the purpose served hoarding it? Why not instead get credit for the thinking and help shape the public discourse before the analysis ages to irrelevance" [9]?

When looking at some of the hoarded data, it is easy to spot things such as websites, articles downloaded from journals or even emails. Like hoarders who print the articles and save the articles, the odds of them going back to the paper or computer file is minimal, especially if they are filing when retrieved. Like the old magazine rack holding magazines that are outdated, hoarders feel the need to hang on to online articles. Often they are paper copied, saved and stored. As with a great deal of existing information, it is not current for long, "It gets outdated" [9]. The value of the information declines since the life span of the data is easily decreased and will reduce the effectiveness of the information.

\section{Effectiveness}

People who hoard knowledge impact the effectiveness of the team. Data hoarding robs the organization of effectiveness. When others hoard information, it enhances poor communication practices and implies a false knowledge. First, we should determine what people get out of hoarding information. "People will answer this question in different ways, but often they engage in the behavior because it feels good to help others, they like to look/feel intelligent, they want to achieve a sense of security by decreasing uncertainty, and /or they want to avoid anxiety by not making a final decision" [14]. Often the person who hoards the information is seen by other coworkers as knowledgeable, however, if the information was shared then the project may have been easier, completed ahead of schedule or even better. Information hoarders are not always information sharers. "It's even tougher to try to do your job when people are robbing you of your effectiveness by hoarding information. And, unfortunately, it happens all the time" [3]. 


\section{Issues in Information Systems}

Volume 13, Issue 2, pp. 90-95, 2012

Organizations sometimes create a hoarding culture. The effectiveness of one department may deter another by not sharing information or by simply using more server space. Looking at the shared drive of an organization often can prove how much unnecessary information is taking up space. Another consideration is that the department does not necessarily hoard but may not maintain files and space adequately. For whatever reason information is over held in reserve, it needs to be reviewed periodically. Governance is a challenge for most organizations. If the organizational policies are to review or clean up files (for example) every six months, habits of the hoarders may encourage the behavior to decrease. "The irony is that although there are always individual hoarders out there, often it's the organization that often encourages this kind of aberrant behavior" [3]. With less files to look through, and setting up an organizational wide policy on how the files will be labeled, reviewed and deleted, accessibility and sharing will be easier for all of the users.

\section{Sharing data/information}

As we have discussed, there are several reasons why a person or organization would hoard information. "The Research (Zweig \& Brodt, 2005) found that people with critical knowledge will often protect it as if it were their own property and they will engage in different behaviors to hide knowledge for others" [2]. Within a department, information may be restricted, but by leaving the information in silos, the decision making process may be curtailed by the lack of sharing data. If information is not free flowing, one person feeling the need to hoard may cause issues throughout the organization causing improper decision making or lack of decision making.

Also, consider the person who does not share information. "Creating and sharing knowledge are intangible activities that can neither be supervised nor forced out of people" [8]. The dilemma of enforcing knowledge or information sharing may not be as easy as cleaning up the hoarding itself. The process needs to be willing and open, not forced. Individuals need to understand the value of sharing information; not by hoarding information they are becoming less expendable or seen with more power. The power is in sharing the information that produces the knowledge.

People or organizations may hoard due to thinking they will not receive their return of knowledge. "The fundamental issue with public goods is the 'free rider' problem, whereby certain individuals will utilize a public good without contributing their fair share" [11]. This is no longer for the good of the group; it is narrowed down to the doers and the non-doers. Knowledge sharing should be a continuum of ideas, support, communications and the task at hand, but this will not be the case if the individual or organization hoards. Silos are just a portion of what happens to organizations that function as departmental hoarders.

On the other side of willing data sharing, is the Right to Know laws. In Pennsylvania, the law states: "Record Information, regardless of physical form or characteristics, that documents a transaction or activity of an agency and that is created, received or retained pursuant to law or in connection with a transaction, business or activity of the agency. The term includes a document, paper, letter, map, book, tape, photograph, film or sound recording, information stored or maintained electronically and a data-processed or image-processed document" [15]. For the Federal government, the Freedom of Information Act (FOIA) "is a law that gives you the right to access information from the federal government. It is often described as the law that keeps citizens in the know about their government" [5]. This information may be accessed by citizens, via a process enacted by the legislation. Keep in mind that under certain circumstances, anyone may access your information.

\section{Productivity}

Everyone likes having immediate access to information they are in search of. Time can often be given a dollar value or it may be related to productivity time. Changes to types of data collected have increased productivity and investments. For example "a [the] competitor had made massive investments in its ability to collect, integrate, and analyze data form each store and every sales unit and had the ability to run a myriad real world experiments. At the same time, to re-order hot selling items automatically and shifting items from store to store easily. By constantly testing, bundling, synthesizing, and making information instantly available across the organization-from the store floor to the CFO's office - the rival company had become a different, far nimbler type of business" [4]. In this case, 


\section{Issues in Information Systems}

Volume 13, Issue 2, pp. 90-95, 2012

the data relates to profit that may offset the cost for the data. Companies no longer need to provide all the information processing equipment necessary for their business [7]. But recreating the data takes time, money and most of all loss in production. Before the advent of the internet, research was time consuming and corporate spying was more common. Developing and redeveloping product is an open market. "The developments in the IT industry have brought about a paradigm shift in corporate competency: the focus has shifted from long-term, stable business relations to products and services that exactly satisfy customers' demands" [7]. Taking this concept into consideration, it explains why the next generations of products follow quickly or make it to market faster. We are a generation of now and instant gratification, high speed productivity has no room for hoarders. "When people hoard information, they immediately limit the potential for idea generation" [9].The organizational culture may be a hindrance to the productivity.

\section{Knowledge Management Culture}

Some would say the culture of the organization would be the reason for information hoarding. Competitive environments, the management system, or the insecurities of the employees may produce the hoarding environment. The culture is embedded in the organization and behaviors are spawned from these patterns. The untold dynamics of the business may be as hindering as the financial side, sometimes even more so. In a healthy organization, "positive relationship of an organization culture (defined by collaboration, trust, and learning) and knowledge creation processes and conclude that shaping an organization's cultural factors are key to a firm's ability to manage knowledge effectively" [1]. Also, take into consideration "if organizational members share valuable information freely with other members, the organizational responsiveness and effectiveness can be greatly augmented by preventing these members from having the same problems"[ 11]. This could cause a culture shift in the organization if not actively maintained. The environment of sharing enhances the organizational culture, thus permitting a healthy workplace.

"Companies often turn to technology, encouraging employees to build database of knowledge, but if the workers are not willing to cooperate, these efforts are not very productive" [2]. If this approach is taken, and knowledge sharing becomes part of the culture, there is still the possibility of organizational hoarding, which may disrupt the intended healthy process.

Three tenets for building knowledge would be [16]: 1) The one Environment rule-easily available information without having to look for the information, 2) Friction Free Knowledge sharing: Variables with the information may cause friction, this would cause resistance for a worker 3) Embedded Community: taking tools into the work environments so workers may collaborate and share knowledge with others. By collectively developing a process, policy, and an understanding of what shared knowledge is and what it may produce could begin to change an ailing organizational culture. Individuals hoard the information, not the computers or servers. One person may infest an entire department or organization .By taking the three tenets for knowledge building into practice, a positive outcome should develop.

\section{CONCLUSION}

In reviewing the definition of a hoarder, like many complex disorders, "a lot depends on whether the hoarder wants to change" [6]. This relates to the individual or to the organization. As with any type of hoarding, there is no magic "pill", however by "changing thoughts and behaviors" [6] the hoarding may subside if they can accept the change. Corporate culture will play a role in understand what is needed and what is recyclable. What was acceptable or believed to be common practice may enforce the hording or lack of knowledge sharing. Governance or policy may start to reshape the culture of hoarding for individuals, departments or for organizations.

A person's age or experience may have a part in the hoarding process. A "millennial" may not hoard due to they have always known immediate access to information. A person who is less familiar with "instant data" may have fears of loosing information would naturally hoard. If the individual or organization was lacking in sharing process or are hoarding "Social Medial has displaced it" [10]. Knowledge can only be grown if the information is shared and 


\section{Issues in Information Systems}

Volume 13, Issue 2, pp. 90-95, 2012

expanded upon. One idea can be shared with others, possibly producing more than what one person could often even dream of. The more widely shared the information, the more powerful it becomes-and the more important the sharer becomes. [10].

In an organization, cost is a significant factor when considering data hording. Cost can be measured in terms of the financial aspect of paying for more data space, the cost of lost time among employees searching through hoarded data, and the environmental cost of carbon footprints. There are necessary costs the must be incurred in the storage of data. Institutions that are required to keep records such as hospitals or universities for indefinitely lifespan must store data, however it is crucial for organizations to only keep what is necessary or what they are legally bound to keep.

The lifespan of data refers to the length of time data is profitable. Data can be considered profitable as long as it is relevant, usable, and current. If data is considered to be profitable for 3.2 years, after that length of time, the data becomes an expense rather than an asset to an organization and should be discarded. Out dated data that is no longer valuable to an individual or organization becomes ineffective and should be removed or updated.

Hoarding data can create a false sense of uncertainty avoidance among individual members of a team. Excessive data collection can allow a member to feel superiorly knowledgeable among the group, but it does not promote team cohesion or team success. Departments within an organization can hoard data, knowingly or unknowingly, and eventually create a silo effect among the different teams. When certain areas of an organization are not included in data sharing, the effectiveness of the entire organization in compromised. Decision making, and organizational analysis can be negatively affected if data sharing is not consistent and done properly.

Hindrances in productivity are directly impacted by the organization's culture. In this age of information, data access is expected instantaneously. If the volume of stored data on a system is cluttered by useless data, the searching feature becomes slower and thereby slows down productivity. The amount of hoarding the occurs in an organization is based on its culture, meaning the more the organization has embraced technology and the ability of distributing data to proper short-term and long-term storage the more likely it will be to not engage in hoarding.

Cost, Life span of data, effectiveness, sharing of the data, productivity and knowledge management culture all play a part in the daily life of a hoarder. There are many layers to what makes a person or organization a hoarder, however culture plays a role in this act. For some, the fear of losing collected information is a legitimate concern, however with information being easily accessible now, the purpose of hoarding and not sharing seems to be counterproductive. There will always be a level of data clutter around us, but the decline of future data hoarders depends on how we choose to store, organize, retain, share and use data.

\section{REFERENCES}

1. Alavi, M., Kayworth, T., \& Leidner, D. (2005). An Empirical Examination of the Influence of Organizational Culture on Knowledge Management Practices. Journal of Information Systems. Winter 2005-6. 22,( 3) 191-224.

2. Amble, B. (2005). Knowledge Sharing. Retrieved from www.managment- issues.com

3. Bob. (n.d.) Information is Power: Coping with an Information Hoarder at work. Retrieved from www.worplace911.org

4. Brown, B., Chui, M. \& Manyika, J. (2011). Are you ready for the era of 'big data'? McKinsey Quarterly, 2011, 4, 24-35.

5. Freedom of Information Act of 1966. Retrieved from http://www.foia.gov/about.html

6. Harvard Health. (2001). When keeping stuff gets out of hand. Harvard Women's Health Watch. Retrieved from ww.health.Harvard.edu

7. Ishikawa, A., \& Naka, I. (2007). Knowledge Management and Risk Strategies. Hackensack, NJ: World Scientific. 


\section{Issues in Information Systems}

Volume 13, Issue 2, pp. 90-95, 2012

8. Kim, W., \& Mauborgne, R. (1998) Procedural Justice, Strategic Decision Making and the Knowledge Economy. Strategic Management Journal. Vol 19, Nov 4, Special Issue, 323-338.

9. Lowenthal, B. (2010). Hoarding Disorder. Brandweek. 11/1/2010, 51(39), 20.

10. Lowenthal, B. (2010). Hoarding Disorder. Adweek. 51 (39), 20.

11. Marks, p., Polak, P., McCoy, S, \& Galletta, D. (2008). Sharing Knowledge. Communications of the ACM. February, 2008, 51, (2) 60-65.

12. Mayo Clinic (2012) Definition of Hoarding by staff. Retrieved from: http://www.mayoclinic.com/health/hoarding/DS00966

13. Pennsylvania Right-to-Know Law (2009). Retrieved from: http://www.foia.gov

14. Reinardy, R. (2006). Information Hoarding: The Need to Know and Remember. OCD Newsletter. Late Fall, 2006, 14-15.

15. Sloane, S. (2011). The Problem with Packrats: The high cost of Digital Hoarding. Forbes. 3/25/11, 40.

16. Spira, J. (2011). Overload! How too much information is Hazardous to your organization. Hoboken, NY: John Wiley \& Sons, Inc.

17. Zweig \& Brodt, (2005). The Society for Industrial and Organisational Psychology. Dallas, May 5-7. 